\title{
THE TESTING EVALUATION OF SEVERAL DIGITAL TORQUE WRENCHES BY USING A TORQUE WRENCH TESTER
}

\author{
K. Ogushi ${ }^{1}$ \\ ${ }^{1}$ National Metrology Institute of Japan, AIST, Tsukuba, Japan, kji.ogushi@aist.go.jp
}

\begin{abstract}
:
Hand torque wrenches (HTWs) with electrical indicating devices (Type I, Class B defined in ISO 6789-1:2017; called "digital torque wrenches") manufactured by several manufacturers were tested and evaluated. The digital torque wrench is the most accurate in all types of HTWs in general. The reference standard was a torque wrench tester (TWT) with a rated capacity of $50 \mathrm{~N} \cdot \mathrm{m}$. This TWT has been calibrated by using a traceable reference torque wrench (RTW). Testing results are described with some characteristics.
\end{abstract}

Keywords: Torque; Standard; Torque wrench; Torque wrench tester; Testing evaluation

\section{INTRODUCTION}

Although hand torque tools (HTTs) are just tools which fasten elements such as bolts, nuts, and screws, they also have a function of measuring devices which indicate the fastening torque or give out a kind of signal when achieving a pre-set torque.

HTTs include hand torque wrenches (HTWs) and hand torque screwdrivers (HTSs). ISO 6789 [1][2], which is an international standard of the requirement for HTTs, has been revised in 2017. It has been separated into two documentations. Part 1 describes the testing method and the conformity assessment of HTTs, whereas Part 2 describes the calibration method and evaluation of uncertainties. The author supposes that the former is for both manufacturers and customers, and the latter is mainly for manufacturers and calibration laboratories.

There are some excellent investigation results concerned with HTWs. Röske proposed the evaluation method of measurement uncertainty for the HTWs calibrated according to ISO 6789:2003 [3]. Brüge investigated the measurement uncertainty of setting type HTWs when they were used as transfer devices for the comparisons or proficiency tests [4]. Bangi et al. showed a simple uncertainty evaluation method for the calibration results of HTWs in action [5]. Khaled et al. proposed a new calibration procedure for setting type HTWs to reduce the measurement uncertainty differentiating from ISO 6789-1:2017 [6]. Whereas, there might not be detailed investigations for electrical indicating HTWs manufactured by different manufacturers so far.

ISO 6789-1:2017 classifies HTTs as follows:

a) Indicating torque tools (Type I):

1) Class A: HTW, torsion or flexion bar;

2) Class B: HTW, rigid housing, with scale or dial or display;

3) Class C: HTW, rigid housing and electronic measurement;

4) Class D: HTS, with scale or dial or display;

5) Class E: HTS, with electronic measurement.

b) Setting torque tools (Type II):

1) Class A: HTW, adjustable, graduated or with display;

2) Class B: HTW, fixed adjustment;

3) Class C: HTW, adjustable, non-graduated;

4) Class D: HTS, adjustable, graduated or with display;

5) Class E: HTS, fixed adjustment;

6) Class F: HTS, adjustable, non-graduated;

7) Class G: HTW, flexion bar, adjustable, graduated.

In Japan, some customers criticize that conformity assessments are not correct because more significant deviations occur than accuracies declared by manufacturers themselves, particularly in lower capacities of HTWs. Then, the National Metrology Institute of Japan (NMIJ), in the National Institute of Advanced Industrial Science and Technology (AIST) examined testing of HTWs with electrical indicating devices (Type I, Class C defined in ISO 6789-1:2017; called "digital torque wrenches: "DTW"), manufactured by several manufacturers. The DTW is the most accurate in all types of HTWs in general (around $1 \%$, as a relative accuracy declared by manufacturers). The reference standard was a torque wrench tester (TWT) with a rated capacity of $50 \mathrm{~N} \cdot \mathrm{m}$. This TWT has been calibrated by using a reference torque wrench (RTW). The RTW has also been calibrated by using a torque standard machine (TSM) at NMIJ. Some characteristic results are described. 


\section{EXPERIMENTAL METHOD}

\subsection{Experimental apparatus}

The specifications of DTWs which were tested in this research are shown in Table 1. Those specifications are declared by manufacturers on their catalogues. The DTWs were categorized into two groups, which were Group I (rated capacities of $20 \mathrm{~N} \cdot \mathrm{m}$ to $34 \mathrm{~N} \cdot \mathrm{m}$ ) and Group II (rated capacities of $50 \mathrm{~N} \cdot \mathrm{m}$ to $135 \mathrm{~N} \cdot \mathrm{m}$ ). A photograph of these DTWs is shown in Figure 1. Effective lever lengths and sizes of the square drive are different depending on manufacturers. All torque wrenches show their "accuracies" on the catalogues. The definitions are generally unclear, although a few manufacturers define the accuracies as "the relative deviations from the reference values plus one digit." It would be better to recognize the accuracy as the "Maximum permissible relative deviation," which is defined in ISO 6789-1:2017.

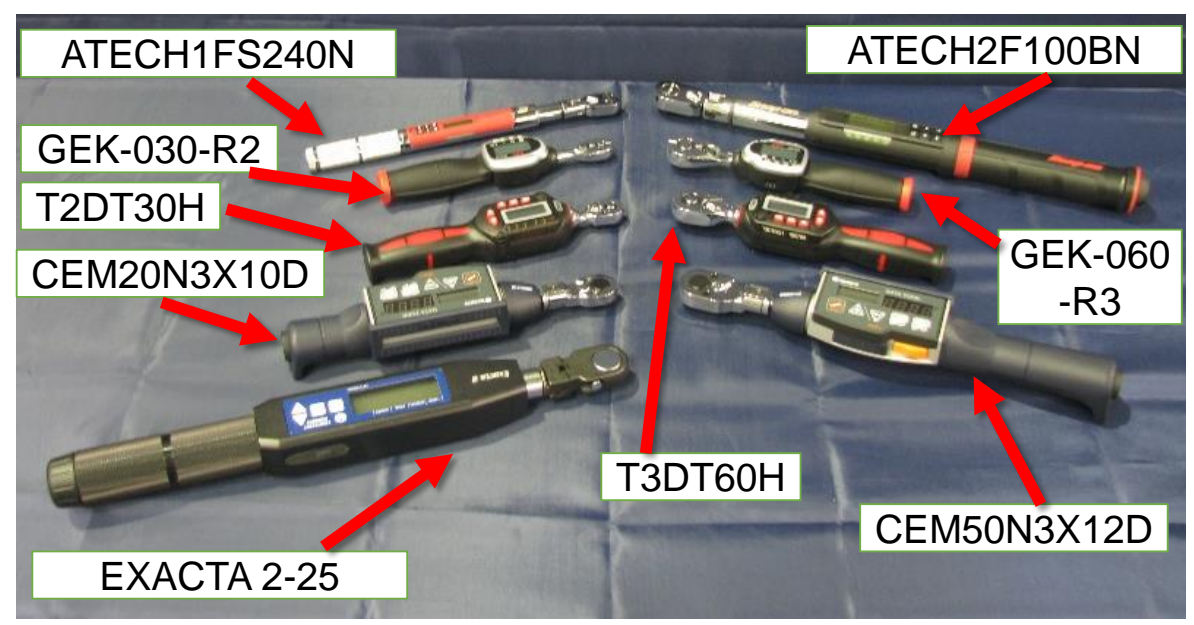

Figure 1: Digital torque wrenches (DTWs) used for the testing and evaluation

Table 1: Specifications of digital torque wrenches

\begin{tabular}{|c|c|c|c|c|c|c|}
\hline \multirow{4}{*}{\multicolumn{2}{|c|}{ Type }} & \multirow{4}{*}{ Manufacturer } & \multirow{2}{*}{\multicolumn{2}{|c|}{ Meas. range }} & & \\
\hline & & & & & \multirow{3}{*}{\multicolumn{2}{|c|}{$\begin{array}{c}\text { Effective } \\
\text { length } \\
\mathrm{mm}\end{array}$}} \\
\hline & & & Min & Max & & \\
\hline & & & \multicolumn{2}{|c|}{$N \cdot m$} & & \\
\hline & ATECH1FS240N & Snap-on Inc. & $\begin{array}{ll}--- \\
\end{array}$ & 30 & \multicolumn{2}{|c|}{237} \\
\hline & GEK-030-R2 & Kyoto Tool Co., Ltd. & 6 & 30 & \multicolumn{2}{|c|}{150} \\
\hline & T2DT30H & TONE Co., Ltd. & 6 & 30 & \multicolumn{2}{|c|}{160} \\
\hline & EXACTA 2-25 & Sturtevant Richmont & --- & 34 & \multicolumn{2}{|c|}{317} \\
\hline 5 & CEM20N3X10D & Tohnichi Mfg. Co., Ltd. & 4 & 20 & \multicolumn{2}{|c|}{217} \\
\hline \multirow{2}{*}{\multicolumn{2}{|c|}{ Type }} & \multirow[t]{2}{*}{ Manufacturer } & \multirow{2}{*}{\begin{tabular}{|c|} 
Square \\
drive \\
$/ \mathrm{mm}$ \\
\end{tabular}} & \multirow{2}{*}{$\begin{array}{l}\text { Reso- } \\
\text { lution } \\
/ \mathrm{N} \cdot \mathrm{m}\end{array}$} & \multicolumn{2}{|c|}{$\begin{array}{c}\text { Accuracy }^{* 1)} \\
/ \pm \%\end{array}$} \\
\hline & & & & & $\mathrm{CW}$ & CCW \\
\hline & ATECH1FS240N & Snap-on Inc. & 6.3 & 0.01 & 2 & 3 \\
\hline & GEK-030-R2 & Kyoto Tool Co., Ltd. & 6.3 & 0.02 & 4 & 4 \\
\hline 3 & T2DT30H & TONE Co., Ltd. & 6.3 & 0.01 & 3 & 3 \\
\hline 4 & EXACTA 2-25 & Sturtevant Richmont & 10 & $0.01^{* 3)}$ & 1 & 1 \\
\hline & CEM20N3X10D & Tohnichi Mfg. Co., Ltd. & 10 & 0.02 & $1^{2)}$ & $1^{2)}$ \\
\hline \multicolumn{7}{|c|}{ Group II } \\
\hline \multirow{3}{*}{\multicolumn{2}{|c|}{ Type }} & \multirow{3}{*}{ Manufacturer } & \multicolumn{2}{|c|}{ Meas. range } & \multirow{3}{*}{\multicolumn{2}{|c|}{$\begin{array}{c}\text { Effective } \\
\text { length } \\
\mathrm{mm}\end{array}$}} \\
\hline & & & Min & Max & & \\
\hline & & & \multicolumn{2}{|c|}{$\mathrm{N} \cdot \mathrm{m}$} & & \\
\hline & ATECH2F100BN & Snap-on Inc. & --- & 135 & \multicolumn{2}{|c|}{347} \\
\hline & GEK-060-R3 & Kyoto Tool Co., Ltd. & 12 & 60 & \multicolumn{2}{|c|}{150} \\
\hline & T3DT60H & TONE Co., Ltd. & 12 & 60 & \multicolumn{2}{|c|}{165} \\
\hline & CEM50N3X12D & Tohnichi Mfg. Co., Ltd. & 10 & 50 & \multicolumn{2}{|c|}{254} \\
\hline \multirow{2}{*}{\multicolumn{2}{|c|}{ Type }} & \multirow[t]{2}{*}{ Manufacturer } & \multirow{2}{*}{\begin{tabular}{|c|} 
Square \\
drive \\
/ mm \\
\end{tabular}} & \multirow{2}{*}{$\begin{array}{l}\text { Reso- } \\
\text { lution } \\
/ \mathrm{N} \cdot \mathrm{m}\end{array}$} & \multicolumn{2}{|c|}{$\begin{array}{c}\text { Accuracy }^{* 1)} \\
/ \pm \%\end{array}$} \\
\hline & & & & & CW & CCW \\
\hline & ATECH2F100BN & Snap-on Inc. & 10 & 0.1 & 2 & 3 \\
\hline & GEK-060-R3 & Kyoto Tool Co., Ltd. & 10 & 0.05 & 3 & 3 \\
\hline & T3DT60H & TONE Co., Ltd. & 10 & 0.01 & 3 & 3 \\
\hline & CEM50N3X12D & Tohnichi Mfg. Co., Ltd. & 10 & 0.05 & $1^{2)}$ & $1^{2)}$ \\
\hline
\end{tabular}

A TWT of DOTE50N4, manufactured by TOHNICHI Mfg. CO., LTD., was used as a reference standard for these tests. A photograph of the TWT is shown in Fig. 2. The rated capacity and resolution of the TWT are $50 \mathrm{~N} \cdot \mathrm{m}$ and $0.005 \mathrm{~N} \cdot \mathrm{m}$. A maximum effective length is $410 \mathrm{~mm}$. The accuracy declared on the catalogue is $\pm 1 \%+1$ digit. Nevertheless, the uncertainty of calibration of the TWT was evaluated by using a reference torque wrench (RTW). The RTW is the combination of TTS $/ 100 \mathrm{Nm}$ (as a torque transducer in the shape of torque wrench) and MGCplus with ML38 (as an indicator/amplifier), as shown in Fig. 3. An appearance of the calibration of TWT by using RTW is also shown in Fig. 4. The RTW was calibrated by using a torque standard machine (TSM) at NMIJ as well. Therefore, the traceability of measurement was utterly established in the series of experiments.

Relative expanded uncertainties of the RTW calibration by using the TSM were as follows for clockwise $(\mathrm{CW})$ and counterclockwise $(\mathrm{CCW})$ torques:

CW: $\quad 0.045 \%(5 \mathrm{~N} \cdot \mathrm{m} \sim 100 \mathrm{~N} \cdot \mathrm{m})$

CCW: $\quad 0.056 \%(-5 \mathrm{~N} \cdot \mathrm{m} \sim-100 \mathrm{~N} \cdot \mathrm{m})$

Relative expanded uncertainties of the TWT Calibration by using the RTW were as follows:

CW: $\quad 0.38 \%(5 \mathrm{~N} \cdot \mathrm{m} \sim 50 \mathrm{~N} \cdot \mathrm{m})$

CCW: $\quad 0.51 \%(-5 \mathrm{~N} \cdot \mathrm{m} \sim-50 \mathrm{~N} \cdot \mathrm{m})$ 


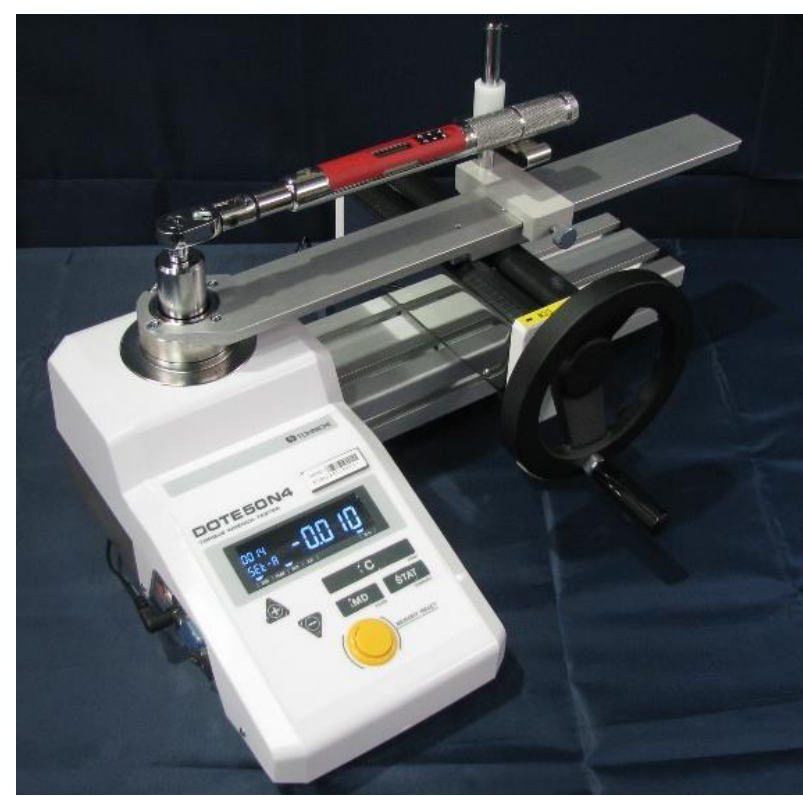

Figure 2: The torque wrench tester (TWT) used as a reference standard

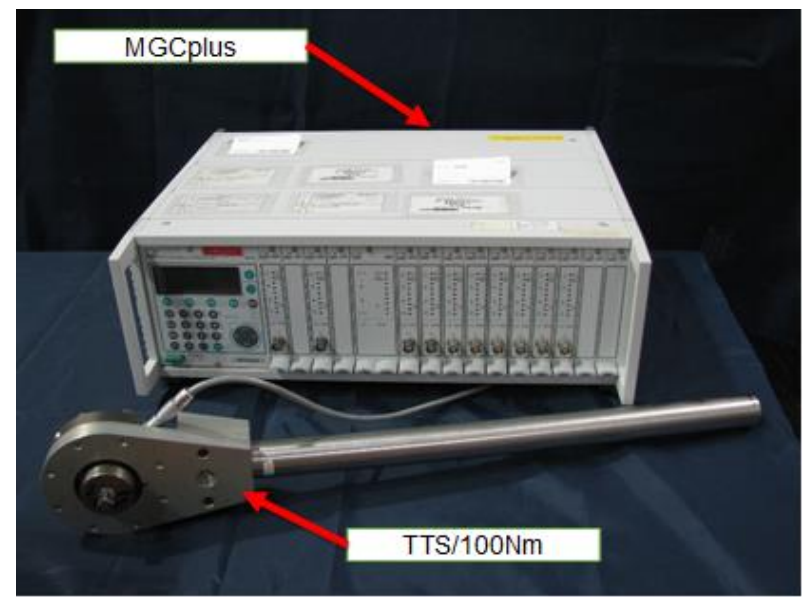

Figure 3: The reference torque wrench (RTW) used for the calibration of the torque wrench tester (TWT)

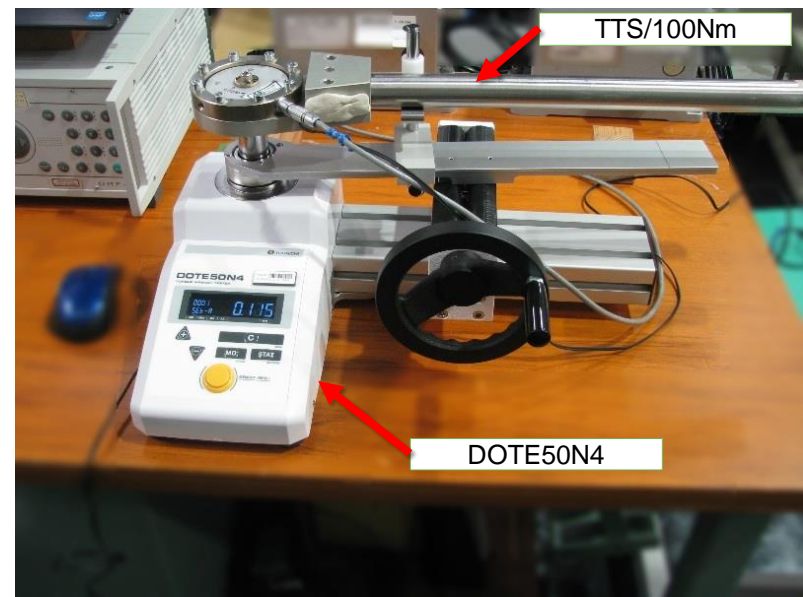

Figure 4: The calibration of the TWT using the RTW as a reference standard

The reference [7] and [8] describe the detailed procedures of calibrations and uncertainty evaluations for the RTW and TWT, respectively. The uncertainty of the calibration for the TWT includes the uncertainty contribution due to the indicating error in the case of the display with the unit of torque. Then, the indicated values of the TWT were not corrected in the testing of HTWs afterward. The maximum values of indicating errors were $0.12 \%$ for $\mathrm{CW}$ and $0.13 \%$ for $\mathrm{CCW}$. The normative requirement that "The maximum measurement error of the torque measurement device shall not exceed $1 / 4$ of the claimed maximum permissible relative deviation of the torque tool at each target value." in ISO 6789-1:2017, was satisfied as the maximum permissible relative deviation is $4 \%$ in this experiment [1].

\subsection{Experimental procedure}

In the testing of HTWs, the effective lever lengths set out in the TWT were adjusted according to the specification of each HTW. Besides, both the horizontal positions of HTW and TWT were adjusted by using just a level.

The testing was conducted according to the procedure written in ISO 6789-1:2017. Here, the testing was separated to $\mathrm{CW}$ and $\mathrm{CCW}$. One preloading was carried out by the maximum torque of that testing beforehand. Five times at $6 \mathrm{~N} \cdot \mathrm{m}$, five times at $12 \mathrm{~N} \cdot \mathrm{m}$, and five times at $20 \mathrm{~N} \cdot \mathrm{m}$ were loaded out for the Group I. Five times at $12 \mathrm{~N} \cdot \mathrm{m}$, five times at $30 \mathrm{~N} \cdot \mathrm{m}$, and five times at $50 \mathrm{~N} \cdot \mathrm{m}$ were loaded out for the Group II. The torque steps were a bit different from the requirement of ISO 6789-1:2017 (at the lowest specified torque value, at approx. $60 \%$, and finally at $100 \%$ of the maximum torque). Therefore, the experimental results cannot be directly compared to the maximum permissible relative deviation according to the ISO document. The indications of the TWT was read out when the readings of HTWs strictly coincided with the target values. The another consecutive five times loading was conducted after complete unloading to zero when overloading accidentally occurred.

Besides, the author conducted an extra testing at the maximum step of $\mathrm{CCW}$ torque, changing the effective length of the lever to $5 \mathrm{~mm}$ longer than setting average length.

\section{RESULTS AND DISCUSSION}

\subsection{Relative deviation}

Figures 5 and 6 show relative deviations of the TWT indications from the indication values of DTWs for Group I and II, respectively. The symbols of DTW-A to DTW -E, and DTW-K to DTW-N are just random. They are not related to the order in Table 1.

It was found that almost all DTWs tested had a small repeatability with simple five measurements at each torque step. There was a little more extensive repeatability at the $+6 \mathrm{~N} \cdot \mathrm{m}$ step of DTWA and at the $+12 \mathrm{~N} \cdot \mathrm{m}$ step of DTW-L. 


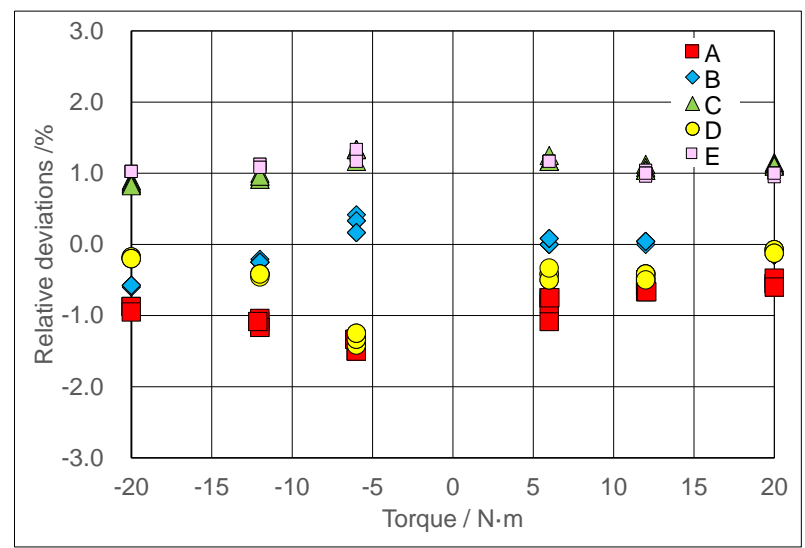

Figure 5: Testing results for Group I

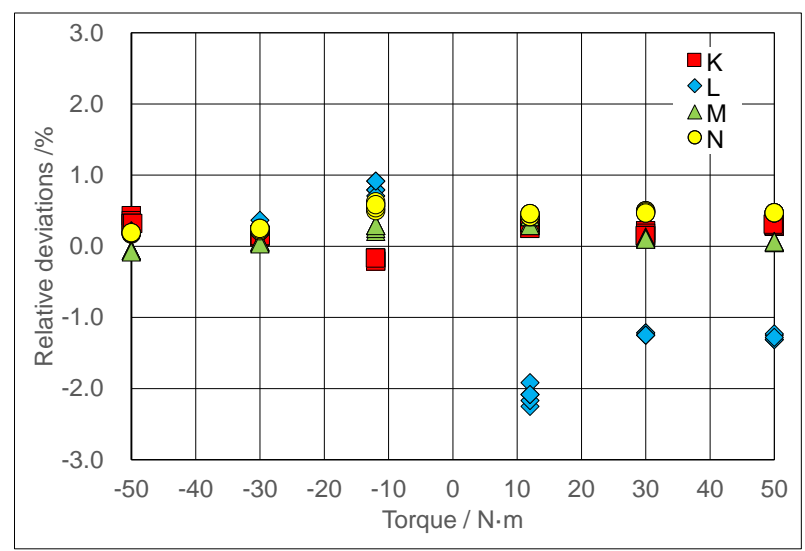

Figure 6: Testing results for Group II

The quantities of relative deviations depended on the type of DTWs. One was nearly zero deviations, whereas the other was more than $2 \%$ deviations. The reason for such different deviations probably comes from the different pathways of the traceability, different mechanisms of DTWs, or both. All relative deviations were within the accuracy, declared in the catalogues of manufacturers in either case.

The maximum permissible relative deviation for DTWs is $4 \%$, according to ISO 6789-1:2017. Then, the maximum measurement error of TWT should be equal or less than $1 \%$. However, many manufacturers insist that the accuracy of DTWs of less than $4 \%$, e.g., $1 \%, 2 \%$, or $3 \%$. In such cases, the maximum measurement error of TWT should also be much smaller than $1 \%$. In the strictest case, $0.25 \%$ of the measurement error is required. The value of error is quite difficult to be achieved, especially at the lower range of torque values $(5 \mathrm{~N} \cdot \mathrm{m}$ or smaller).

\subsection{Influence of changing the effective length}

At the maximum step of CCW torque $(-20 \mathrm{~N} \cdot \mathrm{m}$ for Group I and $-50 \mathrm{~N} \cdot \mathrm{m}$ for Group II), the effective lengths (loading points) of the lever were changed to $5 \mathrm{~mm}$ longer than original effective lengths. The relative deviations of average values for five measurements are shown in Figs. 7 and 8.

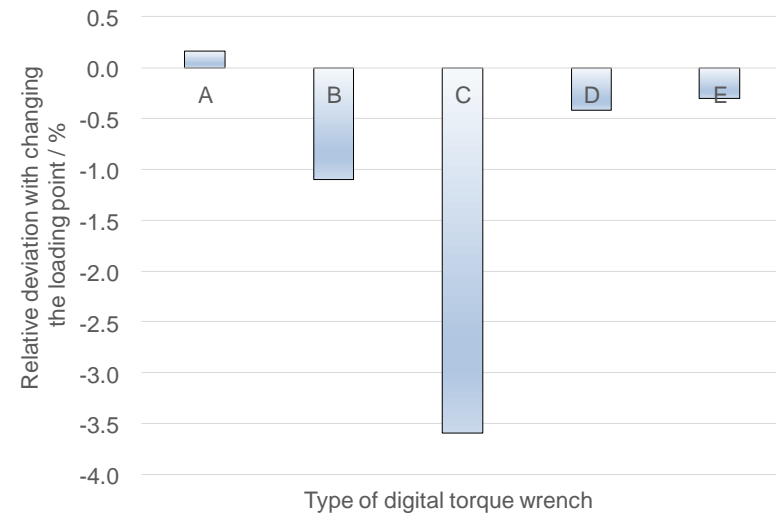

Figure 7: Relative deviations when changing the position of loading point to $5 \mathrm{~mm}$ outward in the case of Group I

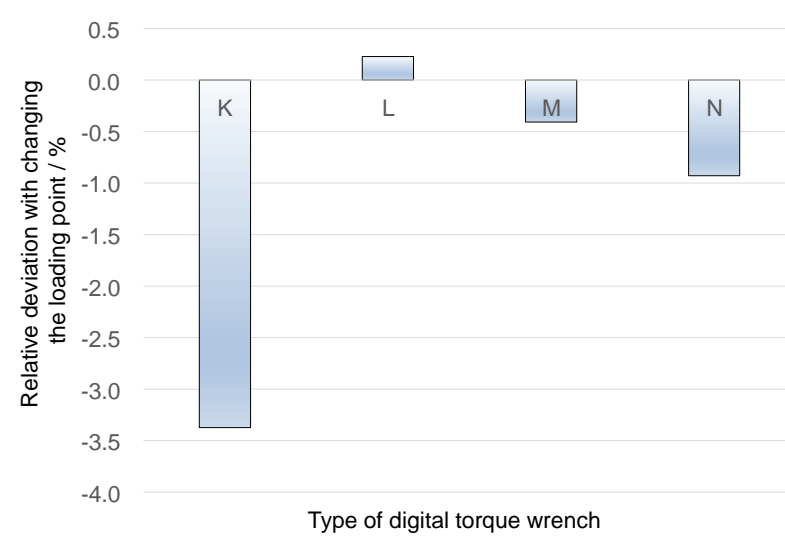

Figure 8: Relative deviations when changing the position of loading point to $5 \mathrm{~mm}$ outward in the case of Group II

The uncertainty contribution due to the variation of the force loading point should be considered for the total uncertainty of HTTs according to ISO 6789-2:2017 [2] (The concept of the uncertainty of "calibration" but not "testing results" are introduced in part 2 of this standard). The variation value should be obtained by measuring ten times at $10 \mathrm{~mm}$ on either side of the center of the handhold position or the marked loading point for the lower limit torque values.

Although the measurement method in this experiment was a bit different from ISO 6789-2:2017, we could obtain the tendency of this effect.

It was found that there were quite large deviations in some DTWs from Figs. 7 and 8. Only $5 \mathrm{~mm}$ change of the lever length caused more than $3 \%$ deviations. It might be ascribable to the difference of structure inside of each DTW.

There are some types of structure in DTWs as follows, for example:

(1) Measuring the shear strain at the twisting axis,

(2) Measuring the bending strain of an elastic hinge rod inside, and

(3) Measuring the bending strain of an elastic hinge rod but putting an additional pivot and shortened the hinge length. 
Those differences of structure might affect the influence of changing the effective length of the lever.

Finally, the handhold shapes of DTWs possibly affect the influence of lever length change. DTWs tested in this study have various shapes at the handhold grip (loading point) such as rounded, inclined, grooved, or protruded ones.

\section{CONCLUSION}

The author examined the testing of hand torque wrenches (HTWs) with electrical indicating devices (Type I, Class C defined in ISO 6789-1:2017; called "digital torque wrenches: DTW"), manufactured by several manufacturers. The torque wrench tester (TWT) was used for the reference standard, which was calibrated traceable to the national torque standard. All relative deviations were found to be within the accuracy declared in the catalogues of manufacturers. However, there were quite large deviations in some DTWs when the effective lengths (loading points) of the lever were changed to $5 \mathrm{~mm}$ longer than original effective lengths. The structure problem of DTWs might affect the total uncertainty of calibration when evaluated by using ISO 6789-2:2017.

The author is going to examine the testing results of DTWs with different TWTs which have different pathways of traceability, as the next stage.

\section{ACKNOWLEDGMENT}

The author appreciates Mr. Sakae Kimura, who is the technical staff in NMIJ, for his contribution to data acquiring, photographing, and processing.

\section{REFERENCES}

[1] ISO 6789-1, Assembly tools for screws and nuts Hand torque tools - Part 1: Requirements and methods for design conformance testing and quality conformance testing: minimum requirements for declaration of conformance, International Standard Organization, 2017.

[2] ISO 6789-2, Assembly tools for screws and nuts Hand torque tools - Part 2: Requirements for calibration and determination of measurement uncertainty, International Standard Organization, 2017.

[3] D. Röske, ISO 6789:2003 Calibration results of hand torque tools with measurement uncertainty some proposals, Proc. XX IMEKO World Congress, Busan, RP. Korea, 9 - 12 September 2012.

Online [accessed 20200727]:

https://www.imeko.org/publications/wc2012/IMEKO-WC-2012-TC3-O34.pdf

[4] A. Brüge, Operating conditions for transfer clicktorque wrenches, Proc. IMEKO $22^{\text {nd }}$ TC $3,15^{\text {th }}$ TC5 and $3^{\text {rd }}$ TC 22 Int. Conf., Cape Town, RP. South Africa, 3 - 6 February 2014.

Online [accessed 20200727]:

https://www.imeko.org/publications/tc32014/IMEKO-TC3-2014-017.pdf

[5] J. O. Bangi, S. M. Maranga, S. P. Nganga and S. M. Mutuli, Torque wrench calibration and uncertainty of measurement, Proc. IMEKO $22^{\text {nd }}$ TC $3,15^{\text {th }}$ TC5 and $3^{\text {rd }}$ TC 22 Intr. Conf., Cape Town, RP. South Africa, 3 - 6 February 2014.

Online [accessed 20200727]: https://www.imeko.org/publications/tc32014/IMEKO-TC3-2014-030.pdf

[6] K. M. Khaled and S. M. Osman, Improving the new ISO 6789:2017 for setting torque tools - Proposal, Measurement, 112, 150-156, 2017.

[7] K. Ogushi, A. Nishino, K. Maeda and K. Ueda, Range Expansion of the Reference Torque Wrench Calibration Service to $5 \mathrm{kN} \mathrm{m}$ at NMIJ, Measurement, 45-5, 1200-1209, 2012.

[8] K. Ogushi, A. Nishino, K. Maeda and K. Ueda, Calibration of a torque wrench tester using a reference torque wrench, Proc. SICE Annual Conference, 411-416, Tokyo, Japan, 2011. 